\title{
CLARIFICAÇÃO E CONCENTRAÇÃO DE SUCO DE CAJU POR PROCESSOS COM MEMBRANAS
}

\author{
Fernando C. CIANCI', Luiz Fernando M. SILVA', Lourdes M. C. CABRAL', Virginia M. MATTA
}

\section{RESUMO}

Os processos de separação por membranas têm sido estudados como alternativa aos processos térmicos de conservacão de alimentos, por serem conduzidos em condições amenas de temperatura, permitindo, assim, a preservação de compostos termosensíveis como as vitaminas, por exemplo. O objetivo deste trabalho foi avaliar a utilização da microfiltração e da osmose inversa para a obtenção de suco de caju clarificado e concentrado. O processamento consistiu de três etapas principais: o tratamento enzimático do suco integral; a microfiltração para obtenção do suco clarificado; e a concentração do suco clarificado por osmose inversa. Para o tratamento enzimático, utilizou-se um complexo pectinolítico durante 1 hora. A clarificação foi conduzida em uma unidade de microfiltração tubular e, em seguida, foi utilizado um sistema de osmose inversa, do tipo quadro e placas, para concentrar o suco clarificado. Os fluxos médios de permeado obtidos foram de 184,0 e $11,3 \mathrm{~L} / \mathrm{hm}$ para a microfiltração e a osmose inversa, respectivamente. Os taninos, responsáveis pela adstringência do suco, foram retidos pela membrana de microfiltração e, por isso, não foram detectados nos sucos clarificado e concentrado. O suco clarificado contendo 12,1 Brix foi concentrado até 28,6 Brix. A vitamina C aumentou de $162 \mathrm{mg} / 100 \mathrm{~g}$ no suco clarificado para $372 \mathrm{mg} / 100 \mathrm{~g}$, no concentrado.

Palavras-chave: frutas tropicais; microfiltração; osmose inversa; vitamina C.

\section{SUMMARY}

CLARIFICATION AND CONCENTRATION OF CASHEW APPLE JUICE BY MEMBRANE PROCESSES. Membrane separation processes have been studied as alternatives to heat processes due to their characteristics being conducted at low temperatures, permitting the preservation of heat sensitive compounds such as vitamins. The objective of this work was to evaluate the use of microfiltration and reverse osmosis for obtaining clarified and concentrated cashew apple juice. Processing consisted of three main stages that were an enzymatic treatment of the pulp, microfiltration for obtaining the clarified juice and concentration of clarified juice by reverse osmosis. A pectinolitic enzyme was used during 1 hour for enzymatic hydrolysis. Clarification was carried out in a tubular microfiltration membrane followed by concentration of the clarified juice in an osmosis reverse plate and frame system. The average permeate flux were 184.0 e $11.3 \mathrm{~L} / \mathrm{hm}^{2}$, for microfiltration and reverse osmosis, respectively. Tannins that are responsible for juice astringency were retained by microfiltration membrane and it was not verified in clarified and concentrated

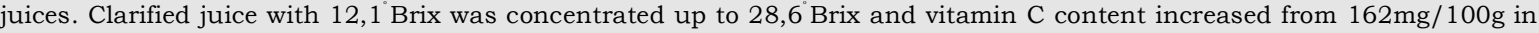
clarified juice to $372 \mathrm{mg} / 100 \mathrm{~g}$ in the concentrate.

Keywords: tropical fruits; microfiltration; reverse osmosis; vitamin C.

\section{1 - INTRODUÇÃO}

O caju é uma fruta tropical, cuja produção, no Brasil, está concentrada no Nordeste, sendo de grande importância social e econômica para a região. A agroindústria do caju no Nordeste produz cerca de 217.062 toneladas de castanha e 2 milhões de toneladas de pseudofruto, a parte carnosa e suculenta do caju, por ano [14]. Apesar da potencialidade do pseudofruto como matériaprima para diversos produtos, cerca de $90 \%$ da sua produção é descartada todos os anos, em função da sua alta perecibilidade e pelo fato do principal negócio do caju ser a comercialização da amêndoa [15]. Entretanto, por ser rica em vitamina $\mathrm{C}$ e compostos fenólicos, substâncias com alto potencial antioxidante, têm despertado o interesse de diferentes grupos de pesquisa $[6,11]$.

Recebido para publicação em 06/04/2005. Aceito para publicação em 31/08/2005(001505).

Faculdade de Engenharia de Alimentos, Universidade Estácio de Sá.E-mail:fernandocianci@supeig.com.br

EMBRAPA Agroindústria de Alimentos. Endereço: Av. das Américas, 29501. CEP: 23020-470, Guaratiba-RJ. E-mail: vmatta@ctaa.embrapa.br

A quem a correspondência deve ser enviada.
O mercado interno consome em torno de 40 mil toneladas de suco de caju [4], o que ainda é muito pouco em relação à produção e a ampliação do mercado exportador depende de fatores como a melhoria tecnológica dos processos de concentração e clarificação, a redução da adstringência, a diminuição do uso de conservadores químicos, além de uma política mercadológica adequada.

Os consumidores de alimentos industrializados têm se preocupado cada vez mais com a qualidade nutricional e sensorial dos mesmos, demandando produtos nutritivos, saborosos e que não contenham conservadores químicos. Os sucos de frutas tropicais atendem a estes requisitos por serem ricos em vitaminas, sais minerais, açúcares e substâncias antioxidantes, além de proporcionarem sabor e aroma agradáveis. Assim, é necessário que as técnicas de processamento e conservação de sucos sejam eficazes em manter nos produtos processados, as características originais das frutas.

As técnicas mais utilizadas na conservação de sucos são a pasteurização, que elimina os microrganismos patogênicos, e a concentração térmica, na qual há redução da atividade de água do produto. Ambos os processos, porém, utilizam temperaturas elevadas que provocam perdas de nutrientes e degradação de cor, além de proporcionarem um sabor de cozido ao suco [9]. 
Com base nestes fatores, tem sido incrementada a busca por processos não-térmicos, que preservem a qualidade dos sucos de frutas [8, 10]. Dentre estes, destacam-se os processos de separação por membranas, como a microfiltração e a osmose inversa $[12,18]$ que por serem conduzidos a temperatura ambiente, não envolvendo mudança de fase, permitem a manutenção das características dos produtos.

O objetivo deste trabalho foi avaliar a utilização dos processos de separação por membranas, a microfiltração e a osmose inversa, no processamento do suco de caju, contribuindo, desta forma, para criar novas alternativas de utilização do pseudofruto e, consequentemente, para a redução das enormes perdas verificadas até o momento.

\section{2 - MATERIAL E MÉTODOS}

\section{1 - Matéria-prima}

Como matéria-prima foi utilizado um lote de $180 \mathrm{~kg}$ de polpa de caju congelada, da marca De Marchi, que foi uniformizada e refinada em despolpador Bonina 0,25df, com peneira de $0,6 \mathrm{~mm}$, obtendo-se o suco integral refinado, que foi novamente congelado até o momento de sua utilização. Para o pré-tratamento enzimático, foi utilizada a enzima Clarex, com atividade pectinolitica.

\section{2 - Procedimento experimental}

O fluxograma esquemático do processamento realizado está apresentado na Figura 1.

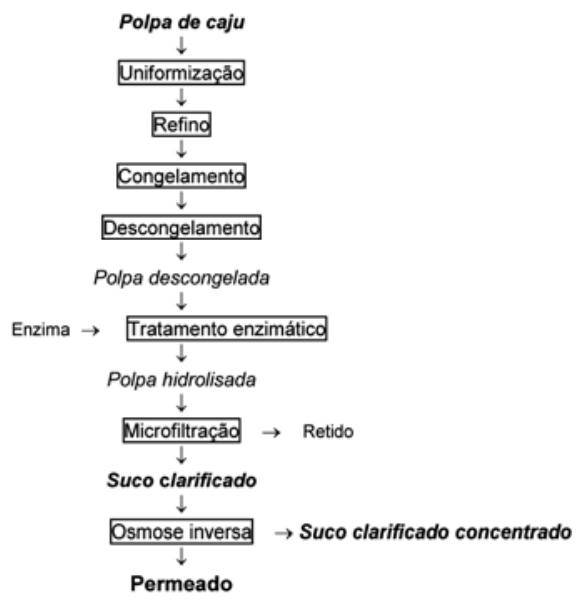

FIGURA 1 - Fluxograma do processo de obtenção de suco de caju clarificado e concentrado por microfiltração e osmose inversa

A polpa de caju foi descongelada e submetida a um pré-tratamento enzimático utilizando $0,025 \%$ (v/v) do produto comercial Clarex, com atividade pectinolítica, durante uma hora, a temperatura de $30^{\circ} \mathrm{C}$, em um vaso multipropósito da Armfield. O suco hidrolisado foi conduzido para um sistema de microfiltração da Koch
Membrane System, composto por uma membrana tubular de polietersulfona, com tamanho de poro de $0,3 \mu \mathrm{m}$ e área filtrante de $0,05 \mathrm{~m}^{2}$. O processo foi conduzido a temperatura de $30^{\circ} \mathrm{C}$ e pressão de $220 \mathrm{kPa}$. O suco clarificado, permeado da microfiltração, foi concentrado em uma unidade de osmose inversa com configuração do tipo quadro e placas, utilizando membranas planas de filme composto, com área de filtração de $0,72 \mathrm{~m}^{2}$ e $95 \%$ de rejeição a $\mathrm{NaCl}$, à pressão de $6,0 \mathrm{MPa}$ e temperatura de $35^{\circ} \mathrm{C}$.

O fluxo de permeado (J) e o fator de concentração volumétrica (FCV), em função do tempo, foram determinados tanto na microfiltração quanto na osmose inversa, utilizando-se as seguintes equações:

$\mathrm{J}=\mathrm{V} / \mathrm{t}$. A

onde:

$\mathrm{V}=$ volume coletado num determinado tempo

$\mathrm{t}=$ tempo durante $\mathrm{o}$ qual a amostra foi coletada

$\mathrm{A}=$ área de filtração da membrana

$\mathrm{FCV}=\mathrm{Va} /(\mathrm{Va}-\mathrm{Vp})$

onde:

$\mathrm{Va}=$ volume da alimentação

$\mathrm{Vp}=$ volume de permeado

O teor de sólidos solúveis foi acompanhado ao longo do processo de concentração. Foram retiradas amostras de todas as etapas do processamento para determinação dos teores de vitamina $\mathrm{C}$, conforme metodologia modificada por SILVA [19], sólidos solúveis, acidez e pH, de acordo com AOAC [1], taninos [7], teor de polpa [16], turbidez nefelométrica em turbidimetro Jundilab e viscosidade em reômetro de cilindros concêntricos Rheomat 30.

\section{3 - RESULTADOS E DISCUSSÃO}

O fluxo médio de permeado da microfiltração do suco de caju, no patamar estabilizado, foi de $184 \mathrm{~L} / \mathrm{hm}^{2}$ e o comportamento do fluxo durante o processamento está apresentado na Figura 2, através da curva com enzima. Na Figura 2 também pode ser observado o efeito do uso da enzima sobre o fluxo de permeado, pela comparação entre o processo com enzima realizado neste trabalho, com um processo anterior sem enzima [13], obtido nas mesmas condições, sem contudo, a realização do prétratamento enzimático. Observa-se, portanto, que a enzima utilizada, com atividade predominantemente pectinolítica, proporcionou um aumento do fluxo permeado de aproximadamente $40 \%$. Foi verificado o perfil clássico dos processos de filtração com membranas, onde a polarização de concentração provoca a queda inicial do fluxo permeado e o acúmulo de material retido sobre a superficie da membrana reduz o fluxo ao longo do tempo de processo, fenômeno conhecido por fouling.

CAMPOS et al. [4], na microfiltração de suco de caju, utilizando o mesmo tipo de sistema de microfiltração e pré-tratamentos com enzimas tanase e celulase, nas con- 


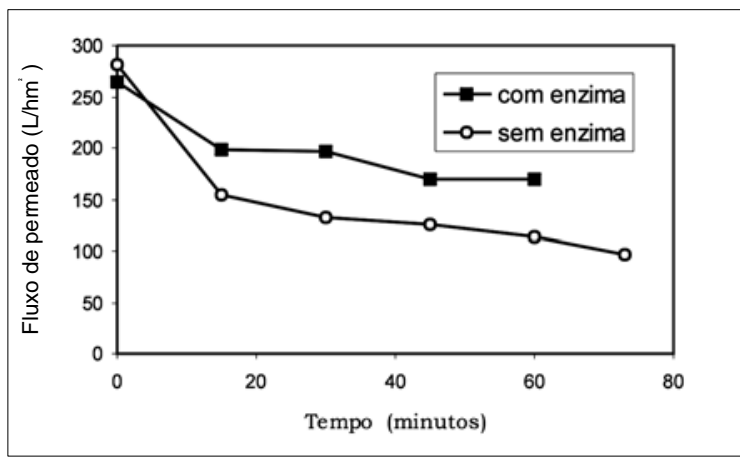

FIGURA 2 - Fluxo de permeado em função do tempo de processo durante a microfiltração de suco de caju com e sem prétratamento enzimático

centrações variando entre $0,05 \%$ a $0,15 \%$, obtiveram fluxos da ordem de $70 \mathrm{~L} / \mathrm{hm}^{2}$, independentemente da concentração e do tipo de enzima utilizada. Ao estudar o fenômeno de fouling durante a ultrafiltração de suco de abacaxi, em membranas de polisulfona de fibra oca, BARROS et al. [2] obtiveram fluxos médios de permeado na faixa de $30 \mathrm{a} 60 \mathrm{~L} / \mathrm{hm}^{2}$, valores bem inferiores aos obtidos no presente trabalho.

$\mathrm{O}$ fator de concentração volumétrica atingido na microfiltração foi de 2,8 na mesma faixa que o obtido por BOTTINO et al. [3], de 2,5 quando processaram suco de tomate com 5,0 Brix, em membranas cerâmicas com tamanho de poro de $0,2 \mu \mathrm{m}$.

O fluxo médio de permeado no processo de osmose inversa foi de $11,3 \mathrm{~L} / \mathrm{hm}^{2}$ e o comportamento deste parâmetro está apresentado na Figura 3, onde se pode observar o forte efeito do fouling. A redução drástica do fluxo de permeado no processo de osmose inversa também foi observada por CASSANO et al. [5], durante a concentração de suco de cenoura clarificado, onde o fluxo variou de $12,0 \mathrm{~L} / \mathrm{hm}^{2}$ no início do processo para $4,0 \mathrm{~L} / \mathrm{hm}^{2}$, no final do mesmo, com um fator de concentração volumétrica de 2,15 .

É importante ressaltar que a grande diferença entre os fluxos médios de permeado para os processos de microfiltração e osmose inversa se deve às características intrinsecas das membranas utilizadas nos dois processos. Ao contrário da microfiltração, que utiliza membranas porosas, na osmose inversa são utilizadas membranas densas e ocorre uma retenção de praticamente todos os sólidos solúveis do produto, aumentando a pressão osmótica da solução e limitando o escoamento.

As características do suco de caju nas diferentes etapas do processamento são apresentadas na Tabela 1 .

A hidrólise enzimática não alterou as características do suco. Os teores de polpa do suco clarificado (SC) e do suco clarificado concentrado (SCC), iguais a zero, demonstram que a microfiltração reteve as macromolécu-

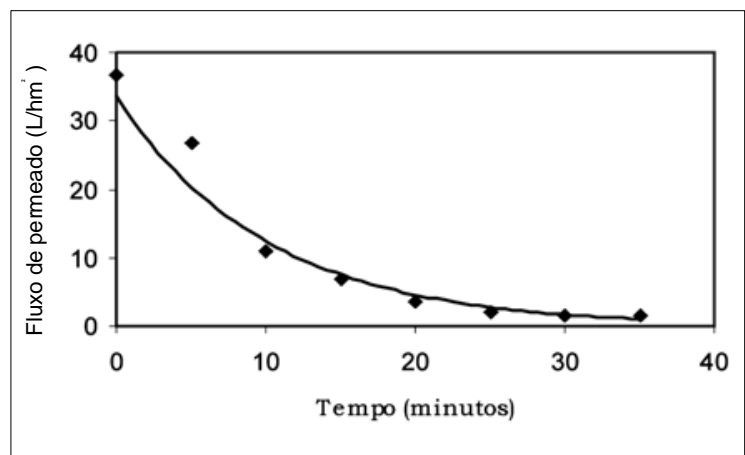

FIGURA 3 - Fluxo de permeado em função do tempo de processo durante a concentração, por osmose inversa, de suco de caju clarificado

TABELA 1 - Características do suco de caju nas diferentes etapas do processo

\begin{tabular}{lcccc}
\hline Parâmetros & SI & SH & SC & SCC \\
\hline Vitamina C (mg/100g) & 189 & 188 & 162 & 372 \\
Sólidos solúveis ( ${ }^{\circ}$ Brix) & 12,5 & 12,7 & 12,1 & 28,6 \\
Acidez (g ác. málico/100g) & 0,43 & 0,43 & 0,37 & 0,84 \\
pH & 4,23 & 4,22 & 4,19 & 4,06 \\
Taninos condensados (mg/100g) & 4,35 & 4,39 & 0 & 0 \\
Turbidez (NTU) & $\mathrm{nr}$ & $\mathrm{nr}$ & 4,10 & $\mathrm{nr}$ \\
Teor de polpa (\%) & 19,6 & 19,1 & 0 & 0 \\
Viscosidade (mPa.s) & 17,7 & 17,2 & 1,3 & $\mathrm{nr}$ \\
\hline nr: não realizado; Sl: suco integral, SH: suco hidrolisado, SC: suco clarificado,
\end{tabular}

nr: não realizado; SI: suco integral, SH: suco hidrolisado, SC: suco clarificado, SCC: suco concentrado.

las que causam o aspecto turvo do suco integral, o que também é constatado pelo baixo valor da turbidez nefelométrica, de 4,1 NTU no suco clarificado. O suco clarificado (SC) apresentou comportamento reológico Newtoniano, com viscosidade na faixa de $1,3 \mathrm{mPa}$.s, ao contrário do suco integral (SI), que apresentou comportamento não-Newtoniano e viscosidade na faixa de $17,7 \mathrm{mPa} . \mathrm{s}$

A diminuição do teor de vitamina $\mathrm{C}$ no suco clarificado (SC) em relação ao do suco hidrolisado (SH) está relacionada tanto à diluição da amostra, em função da recirculação inicial da polpa através do sistema, carreando uma pequena quantidade de água, quanto à oxidação causada pelo bombeamento para a membrana de microfiltração.

Não foi detectada a presença de taninos no suco clarificado (SC) e no suco clarificado concentrado (SCC), evidenciando que a membrana de microfiltração reteve estes compostos. Por conseguinte, esses sucos não apresentaram o sabor adstringente característico do caju. O suco clarificado concentrado (SCC) apresentou maior acidez e menor $\mathrm{pH}$ que o suco clarificado como conseqüência da própria concentração.

O fator de concentração volumétrica obtido na osmose inversa foi de 2,0, com aproximadamente 35 minutos de processo. O tempo para se atingir uma determinada 
concentração é inversamente proporcional à pressão aplicada, o que explica o pequeno tempo de processo utilizado neste trabalho, para a pressão de $6 \mathrm{MPa}$. O teor de sólidos solúveis aumentou durante o processo de concentração (Figura 4). Partindo-se de um suco clarificado com $12,1^{\circ}$ Brix foi obtido um suco com concentração de sólidos solúveis de $28,6^{\circ} \mathrm{Brix}$, portanto, houve um aumento dos sólidos solúveis de 2,4 vezes. O teor de vitamina $\mathrm{C}$ do suco clarificado concentrado (SCC), que foi $372 \mathrm{mg} / 100 \mathrm{~g}$, aumentou cerca de 2,3 vezes em relação ao do suco clarificado (SC). Com base no valor de ingestão diária recomendado (DRI) de vitamina C para um homem adulto, de 90mg [20], o suco de caju clarificado concentrado pode ser considerado uma excelente fonte de vitamina C.

RODRIGUES et al. [17], ao concentrarem suco de camu-camu por osmose inversa, em condições similares às utilizadas neste trabalho, obtiveram um aumento do teor de vitamina $\mathrm{C}$ de cerca de 3,7 vezes e do teor de sólidos solúveis, de 4,0 vezes. O maior fator de concentração se deve ao fato do teor de sólidos solúveis do suco de camucamu integral ser inferior ao do suco de caju. As concentrações finais de sólidos para os dois produtos foram similares, o que era esperado considerando-se que o principal fator limitante para a concentração é a pressão osmótica da solução, que para os sucos de frutas, depende principalmente, do teor de sólidos solúveis.

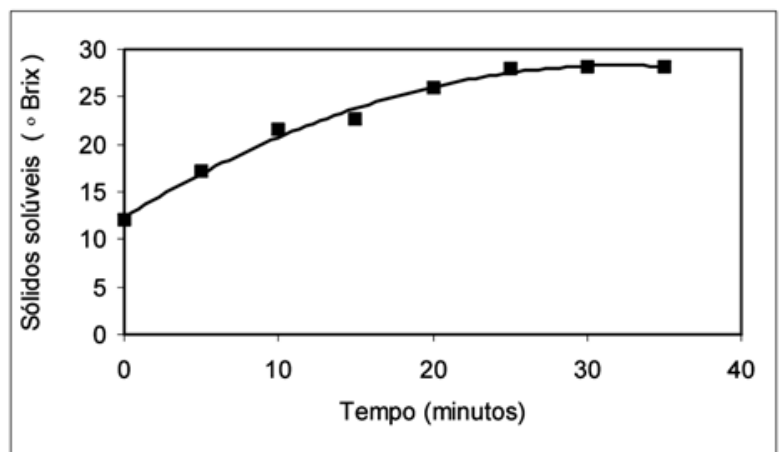

FIGURA 4 - Teor de sólidos solúveis em função do tempo de processo durante a concentração, por osmose inversa, de suco de caju clarificado

\section{4 - CONCLUSÕES}

Os resultados obtidos mostraram que é possivel obter um suco de caju clarificado e concentrado com alto teor de vitamina $\mathrm{C}$, utilizando processos não térmicos, como a microfiltração e a osmose inversa. Também, evidenciam a potencialidade da aplicação da tecnologia de membranas para o processamento do suco de caju, contribuindo para um maior aproveitamento do pseudofruto.

\section{5 - REFERÊNCIAS BIBLIOGRÁFICAS}

[1] AOAC - Association of Official Analytical Chemists. 2000. Official Methods of Analysis of the AOAC International. $17^{\prime \prime}$ ed. Washington: AOAC.

[2] BARROS, S. T. D.; ANDRADE, C. M. G.; MENDES, E. S.; PERES, L. Study of fouling mechanism in pineapple juice clarification by ultrafiltration. Journal of Membrane Science, v. 215, p. 213-224, 2003.

[3] BOTTINO, A.; CAPANNELLI, G.; TURCHINI, A.; VALLE, P. D.; TREVISAN, M. Integrated membrane processes for the concentration of tomato juice. Desalination, v.148: p. 73-77, 2002.

[4] CAMPOS, D. C. P.; SANTOS, A. S.; WOLKOFF, D. B.; MATTA, V. M.; CABRAL, L. M. C.; MODESTA, R. C. D.; COURI, S. Clarificación de jugo de anacardo. Alimentaria, v.334, p.121-124, 2002.

[5] CASSANO, A.; DRIOLI, E.; GALAVERNA, G.; MARCHELLI, R.; DI SILVESTRO, G.; CAGNASSO, P. Clarification and concentration of citrus and carrot juices by integrated membrane processes. Journal of Food Engineering, v. 57: p. 153-163, 2003.

[6] COURI, S.; ALTER, P.; ABREU, F. A. P.; REYNES, M.; BRILLOUET, J. M. Propriedade antioxidante de cinco variedades de pendúnculo de cajueiro anão precoce. In: ENAAL 2003, Rio de Janeiro. Anais... São Paulo: SBAAl, 2003. v. 1, p. 214-214.

[7] DESPHANDE, S. S.; CHERIAN, M. J. Determination of phenolic compound of dry beans using vanillin, redox and precipitation assays. Journal of Food Science, v.52, p.332, 1987.

[8] FRANCHI, M. A.; LEVY, P.; CRISTIANINI, M. Ultra high pressure homogenization of orange juice to control spoilage lactic acid bacteria and Escherichi coli effect of multiple treatments. In: International Conference on High Pressure Bioscience and Biotechnology, 3. 2004, Rio de Janeiro. Book of Abstracts. Rio de Janeiro, p. 118, 2004.

[9] JIAO, B.; CASSANO, A.; DRIOLI. E. Recent advances on membrane processes for the concentration of fruit juices: a review. Journal of Food Engineering, v. 63, p. 303324, 2004.

[10] KOUNIAKI, S.; KAJDA, P.; ZABETAKIS, I. The effect of high hydrostatic pressure on anthocyanins and ascorbic acid in blackcurrants (Ribes nigrum) Flavour and Fragance Journal, v. 19, n.4, p.281-286, 2004.

[11] MARX, F.; LICHTENTHÄLER, R.; RODRIGUES, R. B.; PAPAGIANNOPOULOS, M.; MAIA, J. G. S. Evaluation of the total oxidant scavenging capacities of açai (Euterpe oleracea) and cashew apple (Anacardium occidentale) juices and identification of the active compounds by LCMS. In: SLACA, 5, 2003, Campinas. Anais... Campinas: UNICAMP, 2003.

[12] MATTA, V. M.; MORETTI, R. H.; CABRAL, L. M. C. Microfiltration and reverse osmosis for clarification and concentration of acerola juice. Journal of Food Engineering, v. 61, p. 477-482, 2004.

[13] MATTA, V. M.; CABRAL, L. M. C.; COURI, S.; TERZI, S. C.; REYNES, M.; DORNIER, M. Microfiltração de suco de caju em membranas cerâmicas e poliméricas. In: CIBIA, 
4, 2003, Valparaiso. Anais.... Valparaiso: UTFSM, 2003. p. 153.

[14] Oliveira, V. H. D.; ANDRADE, A. P. S. Produção integrada de caju. Abrindo portas para qualidade. Disponivel em:

<http://www.cnpat.embrapa.br/pif/artigo1.pdf.Acesso em 14 set. 2004.

[15] PAIVA, F. F. A.; GARRUTI, D. S.; SIlVA NETO, R. M. Aproveitamento industrial do caju. Fortaleza: CNPAT/SEBRAE/CE (Embrapa CNPAT, 38), 2000, 85p.

[16] REED, B. J.; HENDRIX, J. R.; HENDRIX, D. L. 1986. Quality Control for Citrus Processing Plants. Florida: Intercit, v1.

[17] RODRIGUES, R. B.; CABRAL, L. M. C.; MENEZES, H. C.; RIOS, G. REYNES, M., DORNIER, M. Evaluation of reverse osmosis and osmotic evaporation to concentrate camu-camu juice (Myrciaria dubia). Journal of Food Engineering, v.63, n.1, p.97-102, 2004.

[18] SA, I. S.; MATTA, V. M.; CABRAL, L. M. C. Concentração de suco de abacaxi através dos processos com membranas. Brazilian Journal of Food Technology, v.6, p.53-62, 2003.

[19] SILVA, M. F. V. 1999. Efeito de Diferentes Tratamentos e Embalagens nas Características da Polpa e na Determinação dos Teores de Ácido Ascórbico e das Antocianinas durante o Armazenamento. CampinasSP, 1999, 224p. Tese (Doutorado). Faculdade de Engenharia de Alimentos, Universidade Estadual de Campinas (UNICAMP).

[20] US NATIONAL ACADEMY OF SCIENCE / INSTITUTE OF MEDICINE. Dietary Reference Intakes for Vitamines C, E, Selenium and Carotenoids. Washington, DC: National Academy Press, 2000, 506p. 